\title{
РОЗРАХУНОК МОНОЛІТНОЇ ПЛИТИ З УРАХУВАННЯМ РЕОЛОГІЧНИХ ВЛАСТИВОСТЕЙ ЗАЛІЗОБЕТОНУ
}

\section{CALCULATION OF A MONOLITHIC PLATE TAKING INTO ACCOUNT THE RHEOLOGICAL PROPERTIES OF REINFORCED CONCRETE}

\author{
Гераськін О.О., магістр, Ротко С.В., к.т.н., доцент, Ужегова О.А., \\ к.т.н., доцент (Луцький національний технічний університет)
}

Heraskin O.O., master, Rotko S.V., Ph.D. in Engineering, Associate Professor, Uzhehova O.A., Ph.D. in Engineering, Associate Professor (Lutsk National Technical University, Lutsk)

Виконано розрахунок монолітної плити перекриття з використанням методу «інженерна нелінійність». Зроблено аналіз впливу понижених жорсткісних характеристик на результати напружено-деформованого стану та підбір армування.

It is well known that the rheological properties of concrete are mainly due to its creep. Even if the load does not change much during the life cycle of the object, the increase in displacements over time due to the creep of concrete significantly affects the stress-strain state of the structure. Over time, it is possible to redistribute the effort between the loaded elements, between the reinforcement and concrete in the cross sections of the elements.

That is, the actual behavior of the structure during the life cycle may differ from that predicted in the design, taking into account only the elastic work of materials. The method of "engineering nonlinearity" used in the calculation makes it possible to determine the real stiffness characteristics of the section. They can be reduced due to plastic deformations of concrete and reinforcement, cracking, etc.

Using this technique, a monolithic reinforced concrete slab of the first floor of the shopping center was calculated for the current loads.

The main parameters of the stress-strain state of the structure of the investigated section of the floor slab in the elastic-linear calculation and calculation using the method of "engineering nonlinearity": moments in the first span, over the first support, in the second span, over the second support, displacement (deflection) in the first and the second span of the plate.

The analysis of the results showed that when applying the method of "engineering nonlinearity" there was some redistribution of forces in the elements of the plate (in the spans the moments increased by $30,8 \%$ and $6,1 \%$, on the supports - decreased by $11,1 \%$ and 35,8\%). Displacements (deflections) more than doubled: in the first span - by 57,6\%, in the second - by $53,13 \%$. 
Due to the redistribution of forces in the spans, the reinforcement increased by $13,9 \%$ and $3,7 \%$, and on the supports - decreased by $11,2 \%$ and $20,4 \%$, respectively. The width of crack opening increased insignificantly - from 2,7\% in the first span to $5,4 \%$ in the second support.

Ключові слова: залізобетон, реологічні властивості, ітераційний метод, інженерна нелінійність.

Key words: reinforced concrete, rheological properties, iterative method, engineering nonlinearity.

Вступ. Сучасне програмне забезпечення дає можливість детального дослідження напружено-деформованого стану елементів конструкцій будівель i споруд. Це дозволяє враховувати нелінійну поведінку конструктивних матеріалів, зокрема, бетону та арматури, 3 метою визначення НДС конструкцій на будь-якому етапі життєвого циклу та економічного проектування.

Актуальність теми дослідження. При розрахунку монолітних залізобетонних конструкцій важливо враховувати той фактор, що залежності напруження - деформації для складових цього композитного матеріалу - бетону та арматури - є нелінійними. Можливість утворення тріщин на ранніх етапах завантаження, навіть на стадії експлуатації, зумовлюють зміну жорсткісних характеристик елементів. Це може спричинити перерозподіл зусиль і значне збільшення переміщень. Крім того, за час експлуатації конструкції внаслідок реологічних властивостей бетону може відбуватись зміна їі напружено-деформованого стану. Адже відомо, що повзучість бетону впливає на перерозподіл напружень між бетоном та арматурою. Цей фактор необхідно враховувати при прогнозуванні роботи конструкцій на заданий термін експлуатації, з метою забезпечення функціональної придатності споруд.

Мета роботи - забезпечити конструктивну безпеку монолітної плити перекриття торгівельного центру, виявити додаткові резерви несучої здатності, знизити матеріаломісткість перекриття, виконавши розрахунок ітераційним методом «інженерна нелінійність».

Основними завданнями дослідження $\epsilon$ :

- $\quad$ дослідити монолітну залізобетонну плиту перекриття із використанням методу «інженерна нелінійність» у ПК ЛИРАСАПР; 
- провести аналіз отриманих результатів при лінійнопружному розрахунку 3 початковими жорсткісними характеристиками i лінійно-пружному із жорсткостями, одержаними на основі режиму «інженерна нелінійність».

Огляд літературних джерел за темою дослідження. Під час навантаження корисним навантаженням у процесі експлуатації у залізобетонних конструкціях починаються розвиватись нелінійні деформації. Останні можуть суттєво впливати на характер розподілу зусиль в елементах конструкцій.

Спочатку розвиток нелінійних деформації призводить до утворення нормальних тріщин в бетоні розтягнутої зони. Далі ці деформації розвиваються в арматурі розтягнутої зони. Далі - в стиснутому бетоні, а перед руйнуванням - і в стиснутій арматурі. Крім того, за час експлуатації конструкції внаслідок реологічних властивостей бетону може відбуватись зміна їі напружено-деформованого стану [3].

Загальновідомо, що реологічні властивості бетону зумовлені, в основному, його повзучістю. Навіть за умови, що навантаження у процесі життєвого циклу об'єкта не зазнає особливих змін, наростання переміщень в часі за рахунок повзучості бетону суттєво впливає на НДС конструкції. 3 часом можливий перерозподіл зусиль між сильно та менш навантаженими елементами, між арматурою і бетоном у перерізах елементів $[1,2]$.

Тобто, реальна поведінка конструкції на протязі життєвого циклу може дещо відрізнятись від прогнозованої при проектуванні з урахуванням лише пружної роботи матеріалів.

ПК ЛІРА-САПР незамінний у наукових дослідженнях, тому що надає можливість виконувати розрахунки конструктивних елементів i розрахункових схем 3 урахуванням фізичної, геометричної, конструктивної і генетичної нелінійності, моделювати процес зведення споруди з урахуванням монтажу чи демонтажу елементів, відстежуючи при цьому зміни напружено-деформованого стану конструкції, фізичних властивостей матеріалів.

Проте розрахунок у нелінійнійній постановці досить трудомісткий i має низку недоліків, адже такий розрахунок:

- може бути виконаний лише одне навантаження, тобто нема можливості використовувати РС3 чи РСН;

- вимагає великих ресурсозатрат, тому що кроковий метод передбачає необхідність багатократного розв'язування систем лінеаризованих рівнянь; 
- вимагає призначення арматури (діаметри, розташування) у кожному перерізі елемента [1].

Натомість, наприкінці 2017p. розробники програмного забезпечення знайомлять користувачів із новим підходом до врахування нелінійної роботи залізобетону - ітераційним методом «інженерна нелінійність» [4].

Цей метод дає можливість визначити реальні жорсткісні характеристики перерізу, які можуть бути зниженими внаслідок реологічних властивостей залізобетону, утворення тріщин тощо.

Досить зручним у користуванні цим методом $\epsilon$ те, що він $\epsilon$ практично тотожним традиційним методам розрахунку в лінійній постановці, до яких так звик звичайний користувач. Тобто, є можливість урахування точнішого розподілу жорсткостей, при цьому виконуючи розрахунок на всі можливі навантаження, отримати розрахункові сполучення зусиль i/чи навантажень, а також - підбір арматури за обчисленими на останній ітерації жорсткостями.

Методика дослідження i постановка задачі. Суть методу «інженерна нелінійність» [4]:

1. Користувач задає «визначальне» навантаження, яке буде визначати напружено-деформований стан конструкції (утворення i розвиток тріщин, пластичні деформації бетону та арматури) напротязі всього часу експлуатації конструкції.

2. Виконується розрахунок на це «визначальне» навантаження у фізично-нелінійній постановці, ітераційним методом, iз одночасним підбором арматури.

3. Результатом ітераційного розрахунку $є$ визначені жорсткісні характеристики на основі НДС кожного перерізу стержневого чи пластинчастого елемента.

4. Наприкінці виконується звичний розрахунок у лінійно-пружній постановці, 3 обчисленими на останньому кроці попереднього розрахунку жорсткісними характеристиками. При цьому розрахунок можливий на будь-які статичні чи динамічні навантаження, з визначенням РС3 чи РСН, підбір чи експертизу перерізів залізобетонних і сталевих елементів, а також конструювання.

За допомогою методу «інженерна нелінійність» [4] була розрахована монолітна залізобетонна плита перекриття першого поверху торгівельного центру на діючі навантаження: 
1. постійне - рівномірно розподілене по всій площі розрахункове навантаження $8,087 \kappa H / \mu^{2}$;

2. змінне квазіпостійне $-2,04 \kappa H / M^{2}$;

3. змінне короткочасне $-2,76 \kappa H / M^{2}$.

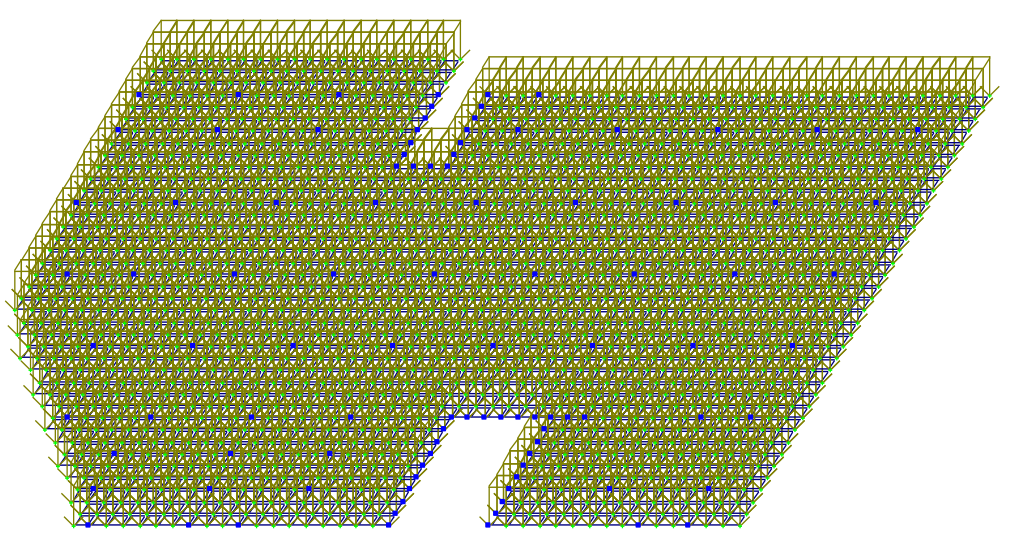

Рис. 1. Розрахункова схема монолітної залізобетонної плити перекриття

Конструктивні характеристики досліджуваної монолітної залізобетонної плити перекриття: плита виготовлена із важкого бетону класу C25/30, армується стержневою арматурою А400С, опирається на монолітні колони перерізом 400х400 мм.

Оскільки плита розбита на велику кількість скінченних елементів, то для дослідження було вибрано ділянку 3 кількома характерними елементами (№№ 46, 72, 100, 129, 159, 160, 192, 226, 261, 298, 337,376, 415, $454,493,532,571,610)$. Нижче наведено мозаїки згинальних моментів для двох варіантів розрахунку. 


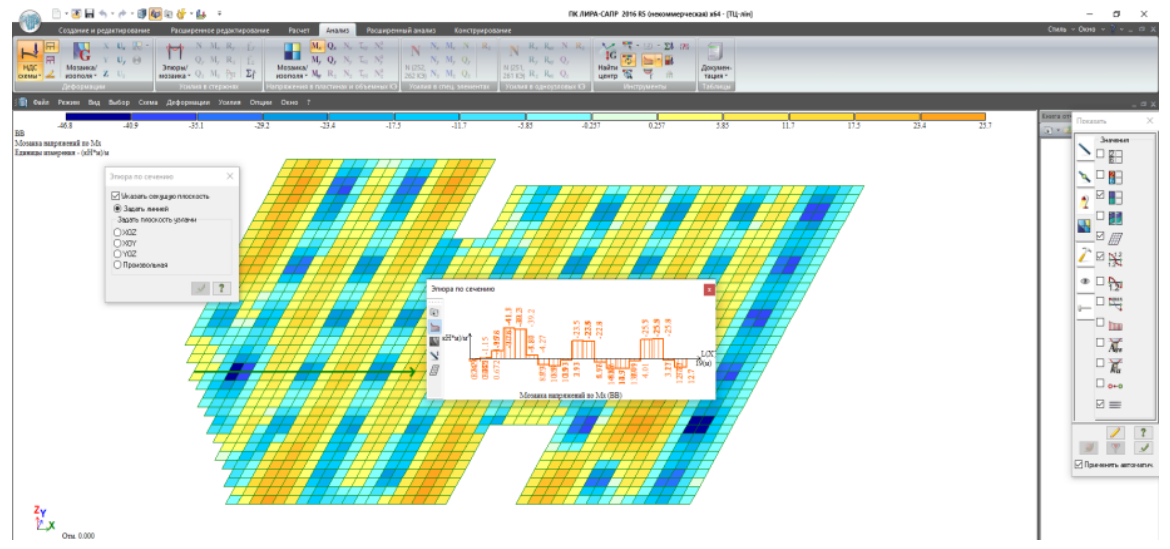

Рис. 2. Мозаїка напружень по Мх (ЛПР)

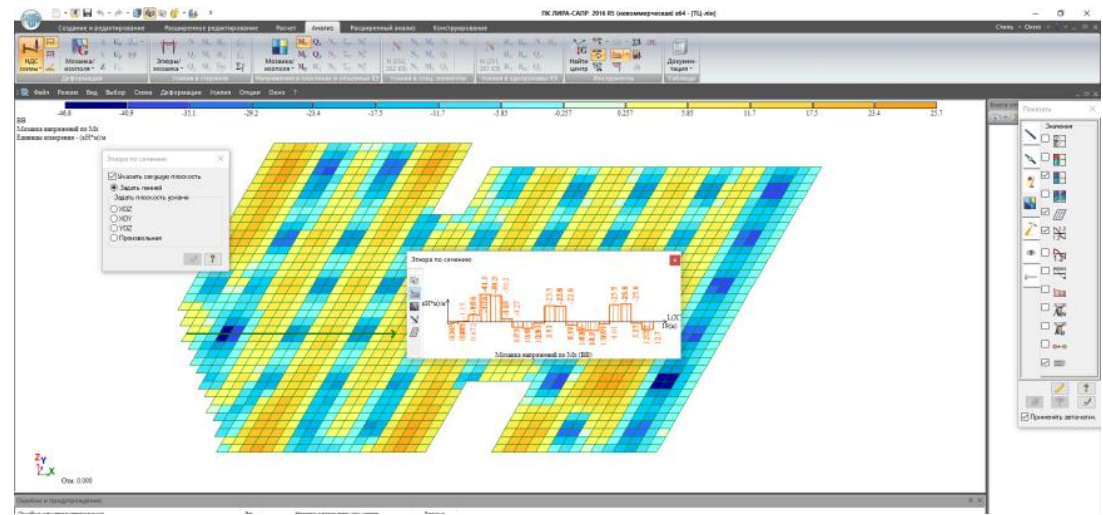

Рис. 3. Мозаїка напружень по Мх (інженерна нелінійність)

Аналіз отриманих результатів. У табл. 1 наведено основні параметри напружено-деформованого стану конструкції досліджуваної ділянки плити перекриття при пружно-лінійному розрахунку та розрахунку 3 використанням ітераційного методу «Інженерна нелінійність»: момент у першому прольоті $\left(\mathrm{M}_{1 \text { пр }}\right)$, момент над першою опорою $\left(\mathrm{M}_{1 о п}\right)$, момент у другому прольоті $\left(\mathrm{M}_{2 п р}\right)$, момент над другою опорою $\left(\mathrm{M}_{2 \text { оп }}\right)$, та переміщення (прогини) у першому та другому прольотах плити. У табл. 2 наведено результати підбору арматури за обох розрахунків. За основу при аналізі результатів було взято метод «Інженерна нелінійність». 
Таблиця 1

Параметри НДС

\begin{tabular}{|c|c|c|c|c|c|c|}
\hline $\begin{array}{r}\text { Параметри } \\
\text { НДС }\end{array}$ & \multicolumn{4}{|c|}{ Згинальні моменти } & \multicolumn{2}{|c|}{$\begin{array}{c}\text { Переміщення } \\
\text { (прогини) }\end{array}$} \\
\hline $\begin{array}{l}\text { Вид } \\
\text { розрахунку }\end{array}$ & $\mathrm{M}_{1 \text { пр }}$ & $\mathrm{M}_{1 \text { оп }}$ & $\mathrm{M}_{2 \text { пр }}$ & $\mathrm{M}_{2 \mathrm{on}}$ & $\begin{array}{c}\text { перший } \\
\text { проліт }\end{array}$ & $\begin{array}{l}\text { другий } \\
\text { проліт }\end{array}$ \\
\hline $\begin{array}{r}\text { Лінійно-пружний } \\
\text { розрахунок } 3 \\
\text { початковими } \\
\text { жорсткостями } \\
\text { (ЛПР) }\end{array}$ & 5,982 & $-63,59$ & 21,724 & $-36,36$ & 6,7 & 0,474 \\
\hline $\begin{array}{r}\text { Лінійно-пружний } \\
\text { розрахунок із } \\
\text { жорсткостями, } \\
\text { отриманими на } \\
\text { основі методу } \\
\text { «інженерна } \\
\text { нелінійність» }\end{array}$ & 8,647 & $-57,23$ & 23,136 & $-26,77$ & 15,8 & 1,01 \\
\hline Похибки ЛПР & $+30,8 \%$ & $-11,1 \%$ & $+6,1 \%$ & $-36,8 \%$ & $+57,6 \%$ & $+53,1 \%$ \\
\hline
\end{tabular}

На основі аналізу таблиці 1 було зроблено висновки:

$\checkmark$ при застосуванні методу «інженерна нелінійність» одержано деякий перерозподіл зусиль в елементах плити:

- у прольотах моменти збільшились на 30,8\% і 6,1\%, відповідно;

- на опорах - зменшились на 11,1\% і 35,8\%, відповідно;

$\checkmark$ переміщення (прогини) зросли на $57,6 \%$ у першому прольоті та на $53,1 \%$ - у другому.

Висновки з аналізу табл. 2:

$\checkmark$ за рахунок перерозподілу зусиль

- у прольотах армування збільшилось на 13,9\% і 3,7\%, відповідно;

- на опорах - зменшилось на 11,2\% і 20,4\%, відповідно;

$\checkmark$ ширина розкриття тріщин збільшилась несуттєво - від 2,7\% у першому прольоті до 5,4\% на другій опорі. 
Таблиця 2

Результати армування

\begin{tabular}{|c|c|c|c|c|c|c|c|c|}
\hline \multirow[b]{2}{*}{$\begin{array}{l}\text { Вид } \\
\text { розрахунку }\end{array}$} & \multirow[t]{2}{*}{ № ел. } & \multirow[t]{2}{*}{$\begin{array}{c}\text { Згин. } \\
\text { момент }\end{array}$} & \multicolumn{4}{|c|}{ Армування } & \multicolumn{2}{|c|}{$\begin{array}{c}\text { Ширина } \\
\text { розкриття } \\
\text { тріщин }\end{array}$} \\
\hline & & & AS1 & AS2 & AS3 & AS4 & $\begin{array}{l}\text { Корот } \\
\text {-коч. }\end{array}$ & $\begin{array}{l}\text { Три- } \\
\text { вала }\end{array}$ \\
\hline \multirow{4}{*}{$\begin{array}{r}\text { Лінійно- } \\
\text { пружний } \\
\text { розрахунок } \\
\text { з початковими } \\
\text { жорсткостями } \\
\text { (ЛПР) }\end{array}$} & $\begin{array}{c}46 \\
(1 п р-т) \\
\end{array}$ & 5,982 & 2,38 & 1,10 & 3,32 & 1,10 & 0,36 & 0,28 \\
\hline & $\begin{array}{c}129 \\
\text { (1оп) }\end{array}$ & $-63,59$ & 1,10 & 13,61 & 1,10 & 11,3 & 0,33 & 0,26 \\
\hline & $\begin{array}{c}454 \\
(2 \pi p-т)\end{array}$ & 21,742 & 3,77 & 1,10 & 1,10 & 1,10 & 0,39 & 0,30 \\
\hline & $\begin{array}{c}337 \\
(20 п) \\
\end{array}$ & $-36,357$ & 1,10 & 7,73 & 1,10 & 8,04 & 0,35 & 0,27 \\
\hline \multirow{4}{*}{$\begin{array}{r}\text { Лінійно-пружний } \\
\text { розрахунок } \\
\text { iз жорсткостями, } \\
\text { отриманими на } \\
\text { основі методу } \\
\text { «інженерна } \\
\text { нелінійність» }\end{array}$} & $\begin{array}{c}46 \\
(1 п р-т)\end{array}$ & 8,6468 & 3,03 & 1,10 & 3,95 & 1,10 & 0,37 & 0,28 \\
\hline & $\begin{array}{c}129 \\
(1 \text { оп) }\end{array}$ & $-57,230$ & 1,10 & 12,35 & 1,10 & 9,83 & 0,33 & 0,26 \\
\hline & $\begin{array}{c}454 \\
(2 \pi p-т)\end{array}$ & 23,136 & 4,04 & 1,10 & 1,10 & 1,10 & 0,39 & 0,30 \\
\hline & $\begin{array}{c}337 \\
\text { (2оп) }\end{array}$ & $-26,766$ & 1,10 & 6,26 & 1,10 & 6,46 & 0,37 & 0,29 \\
\hline
\end{tabular}

\section{Висновки}

1. При проектуванні монолітних конструкцій обов'язково потрібно враховувати реологічні властивості залізобетону, тому що це допоможе виявити реальні переміщення за дії тривалих навантажень. Збільшення деформативності на стадії експлуатації може викликати збільшення внутрішніх зусиль в конструктивних елементах будівель і споруд.

2. Метод «інженерна нелінійність» дає можливість урахування в розрахунках впливу знижених жорсткісних характеристик ЗБК на напружено-деформований стан проектованої будівлі чи споруди. Завдяки цьому $\epsilon$ можливість ефективнішого армування залізобетонних елементів. А ще - отримання наближених до реальних переміщень конструкцій.

3. Урахування нелінійної роботи конструкції допомагає будувати адекватні розрахункові схеми, виявляти резерви несучої здатності конструкцій, забезпечувати конструктивну безпеку. 
4. Важливо, що метод дозволяє суттєво скоротити час на введення даних для розрахунку, а також час самого розрахунку, у порівнянні з кроковим фізично-нелінійним розрахунком.

5. Важливо, що цей метод $є$ доступним у всіх конфігураціях програми ЛИРА-САПР, а кроково-нелінійний метод - лише в комплектаціях PRO і FULL.

\section{References}

1. Barabash M.S. Chy`sel`ne modelyuvannya napruzheno-deformovanogo stanu konstrukcij z uraxuvannyam stadij zhy`ttyevogo cy`klu budivel’ i sporud. Avtoreferat dy`sertaciyi na zdobuttya naukovogo stupenya d.t.n. Odesa, 2014.

2. Bashy`ns`ka O.Yu. Stvorennya rozraxunkovy`x modelei budivel`ny`x konstrukcij pry` vraxuvanni reologichny`x vlasty`vostej zalizobetonu. Avtoreferat dy`sertaciyi na zdobuttya naukovogo stupenya k.t.n. Ky`yiv, 2019.

3. Gorodeczky` A.S., Shmukler V.S., Bondarev A.V. Y`nformacy`onnыe texnology`y rascheta y` proekty`rovany`ya stroy`tel`nыx konstrukcy`j. K.-X., 2003.

4. Gorodeczky ¡ A.S., Barabash M.S. Uchet nely`nejnoj rabotы zhelezobetona v PK LY`RA-SAPR. Metod «Y`nzhenernaya nely`nejnost`». Elektronny`j resurs, kod dostupu: https://help.liraland.ru/984/3279/.

5. Mary`ya Barabash, Dmy`try` $i$ Gorodeczky`, Mary`na Romashky`na Nely`nejnost` v LY`RA-SAPR Algory`tmы sozdany`ya raschetnыx modelej s uchetom nely`nejnoi rabotы konstrukcy`j, 2018, Elektronny`j resurs, kod dostupu: https://help.liraland.ru/984/3426.

6. Programnы kompleks LY'RA-SAPR. Rukovodstvo pol’zovatelya. Obuchayushhy`e pry`merы Vodop`yanov R.Yu., Ty`tok V.P., Artamonova A.E, Romashky`na M.A. Pod redakcy`ej akademy`ka RAASN Gorodeczkogo A.S. Эlektronnoe y`zdany`e, 2017 g., -535 s.

7. Gorodeczky` $i$ A.S., Batrak L.G., Gorodeczky`i D.A., Laznyuk M.V., Yusy`penko S.V. Raschet y` proekty`rovany`e zdany`j y`z monoly`tnogo zhelezobetona. Ky`ev: Y`zdetel`stvo «Fakt», 2004.

8. Perel`muter A.V., Sly`vker V.Y`. Raschet modely` sooruzheny`j y` vozmozhnost`y`x analy`za. M.: AMK, 2007.

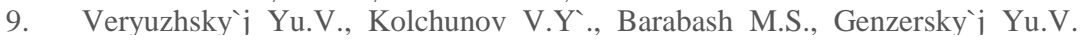
Komp`yuternыe texnology`y proekty`rovany`ya zhelezobetonnых konstrukcy`i. Kursovoe proekty`rovany`e. K.: Kn. Y`zd-vo Nacy`onal`nogo avy`acy`onnogo uny`versy`teta, 2006.

10. Lantux-Lyashhenko A.Y`. LY`RA. Programmnыj kompleks dlya rascheta y` proekty`rovany`ya konstrukcy`i: Uchebnoe posoby`e. K.-M.: Fakt, 2001.

11. Bojl Dzh., Spens Dzh. Analy`z napryazheny`j v konstrukcy`yax pry` polzuchesty`. M.: My`r. 1976.

12. Dorofeev V.S., Kovrov A.V., Kovtunenko A.V., Kushny`r A.M. Opredeleny`e napryazhenno-deformy`rovanogo sostoyany`ya zhelezobetonnыx konstrukcy` s uchetom processov treshhy`noobrazovany`ya. Odesskaya gosudarstvennaya akademy`ya stroy`tel`stva y`arxy`tekturd, 2010.

13. Kachanov L.M. Teory`ya polzuchesty`. M.: Fy`zmatgy`z, 1960.

14. Gorodeczky`i A. S., Evzerov Y`. D. Komp`yuternыe modely` konstrukcy`j. K.: «Fakt», 2005. 344 s.

15. Gorodeczky` prakty`chesky`x raschetax / A. S. Gorodeczky`j, M. S. Barabash // 
Stroy`tel`stvo, matery`alovedeny`e, mashy`nostroeny`e // Sb. nauchn. Trudov. Dn-vsk: PGASA, 2014. Vыр. 77. S. 54-59.

\section{Література}

1. Барабаш М.С. Чисельне моделювання напружено-деформованого стану конструкцій з урахуванням стадій життєвого циклу будівель і споруд. Автореферат дисертації на здобуття наукового ступеня д.т.н. Одеса, 2014.

2. Башинська О.Ю. Створення розрахункових моделей будівельних конструкцій при врахуванні реологічних властивостей залізобетону. Автореферат дисертації на здобуття наукового ступеня к.т.н. Київ, 2019.

3. Городецкий А.С., Шмуклер В.С., Бондарев А.В. Информационные технологии расчета и проектирования строительных конструкций. К.-Х., 2003.

4. Городецкий А.С., Барабаш М.С. Учет нелинейной работы железобетона в ПК ЛИРА-САПР. Метод «Инженерная нелинейность». Електронний peсурс, код доступу: https://help.liraland.ru/984/3279/.

5. Мария Барабаш, Дмитрий Городецкий, Марина Ромашкина Нелинейность в ЛИРА-САПР Алгоритмы создания расчетных моделей с учетом нелинейной работы конструкций, 2018, Електронний ресурс, код доступу: https://help.liraland.ru/984/3426.

6. Програмный комплекс ЛИРА-САПР. Руководство пользователя. Обучающие примеры Водопьянов Р.Ю., Титок В.П., Артамонова А.Е, Ромашкина М.А. Под редакцией академика РААСН Городецкого А.С. Электронное издание, 2017 г., - 535 с.

7. Городецкий А.С., Батрак Л.Г., Городецкий Д.А., Лазнюк М.В., Юсипенко С.В. Расчет и проектирование зданий из монолитного железобетона. Киев: Издетельство «Факт», 2004.

8. Перельмутер А.В., Сливкер В.И. Расчет модели сооружений и возможность их анализа. М.: АМК, 2007.

9. Верюжский Ю.В., Колчунов В.И., Барабаш М.С., Гензерский Ю.В. Компьютерные технологии проектирования железобетонных конструкций. Курсовое проектирование. К.: Кн. Изд-во Национального авиационного университета, 2006.

10. Лантух-Лященко А.И. ЛИРА. Программный комплекс для расчета и проектирования конструкций: Учебное пособие. К.-М.: Факт, 2001.

11. Бойл Дж., Спенс Дж. Анализ напряжений в конструкциях при ползучести. М.: Мир. 1976.

12. Дорофеев В.С., Ковров А.В., Ковтуненко А.В., Кушнир А.М. Определение напряженно-деформированого состояния железобетонных конструкций с учетом процессов трещинообразования. Одесская государственная академия строительства и архитектуры, 2010.

13. Качанов Л.М. Теория ползучести. М.: Физматгиз, 1960.

14. Городецкий А. С., Евзеров И. Д. Компьютерные модели конструкций. К.: «Факт», 2005. 344 с.

15. Городецкий А. С. Учет нелинейной работы железобетонных конструкций в практических расчетах / А. С. Городецкий, М. С. Барабаш // Строительство, материаловедение, машиностроение // Сб. научн. Трудов. Дн-вск: ПГАСА, 2014. Вып. 77. С. 54-59. 